\title{
Cross-modal repetition priming of heterographic homophones
}

\author{
JONATHAN GRAINGER \\ CNRS and University of Provence, Aix-en-Provence, France \\ MARYLINE NGUYEN VAN KANG \\ René Descartes University, Paris, France \\ and \\ JUAN SEGUI \\ CNRS and René Descartes University, Paris, France
}

\begin{abstract}
In two cross-modal priming experiments in French, we investigated the effects of auditorily presented heterographic homophones (an English example is /merd/) on the subsequent visual recognition of the dominant (MADE) and subordinate (MAID) printed forms. When only pronounceable, regular nonwords were used as distractor items in the lexical decision task, both dominant and subordinate forms were facilitated by the homophone prime relative to an unrelated word prime. When pseudohomophones were added among the nonword distractors, dominant targets continued to show facilitation while subordinate targets showed an inhibitory trend. These results provide evidence for inhibitionbased selection in the processing of ambiguous words in the absence of any biasing context.
\end{abstract}

Research over the last two decades on the processing of ambiguous words has concentrated on determining the extent to which sentence context can bias the selection of one or the other meaning. In his review of the literature, Simpson (1994) concluded that, although there is clear evidence for the activation of multiple meanings of ambiguous words, it is also clear that context constrains the degree of activation of these different meanings. Of course, in order to correctly understand a sentence, the contextually appropriate meaning of an ambiguous word must eventually be selected and integrated in the ongoing construction of a sentence-level interpretation (for a recent investigation of sentence-level constraints on lexical ambiguity resolution, see Vu, Kellas, \& Paul, 1998). The present study examines the processing of ambiguous words in the absence of any biasing context.

Figure 1 presents an English example of the type of ambiguity to be examined in the present study: heterographic homophones - that is, words that are spelled differently and have distinct meanings associated with each spelling, but that share a common pronunciation. Thus processing of such stimuli is examined within the general framework of network models of printed word perception (e.g., Jacobs, Rey, Ziegler, \& Grainger, 1998; McClel-

We thank Bob Lorch and two anonymous reviewers for their comments on earlier versions of this work. A special thanks to Madeleine Leveille for help in preparing the present study, and her invaluable service to experimental psychology over the last 40 years. Correspondence should be addressed to J. Grainger, Laboratoire de Psychologie Cognitive, Université de Provence, 29 Av. Robert Schuman, F-13621 Aix-enProvence, France (e-mail: grainger@up.univ-mrs.fr). land \& Rumelhart, 1981; Plaut, McClelland, Seidenberg, \& Patterson, 1996; Van Orden \& Goldinger, 1994). The left-most network presented in Figure 1 is analogous to (and heavily inspired by) the network for heterophonic homographs described in the study of Gottlob, Goldinger, Stone, and Van Orden (1999). According to these authors, the visual presentation of a heterographic homophone (e.g., LEAD) entails simultaneous activation of the different phonologic representations (e.g., /lid/ and /lEd/) plus the corresponding semantic representations. Lateral inhibitory connections ensure that only one pronunciation and meaning becomes significantly active and finally recognized. In other words, the network eventually settles into a stable state where only the dominant phonologic form and dominant meaning remain activated along with the orthographic form.

For the case of auditory presentation of heterographic homophones as tested in the present study, we must now assume that orthographic codes are automatically activated on presentation of a spoken word. There is a large amount of evidence suggesting that such an assumption should hold (Dijkstra, Roleofs, \& Fieuws, 1995; DonnenwerthNolan, Tanenhaus, \& Seidenberg, 1981; Jakimik, Cole, \& Rudnicky, 1985; Seidenberg \& Tanenhaus, 1979; Tanenhaus, Flanigan, \& Seidenberg, 1980; Ziegler \& Ferrand, 1998). Thus, an auditorily presented heterographic homophone (e.g., /meId/) is assumed to initially activate all compatible orthographic forms (e.g., MADE, MAID) and the corresponding semantic representations.

As can be seen in Figure 1, the presence versus absence of lateral inhibition in the network models determines the relative activation levels of the different forms 


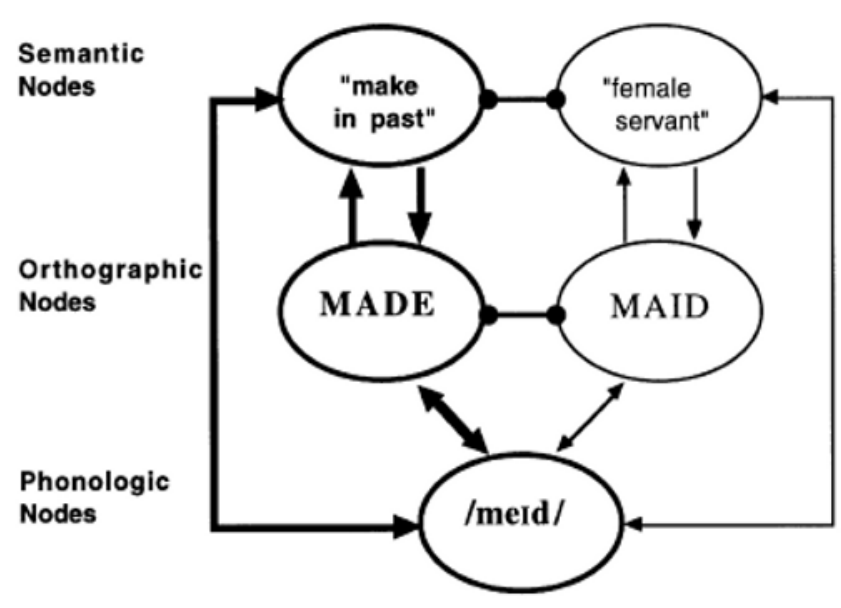

With lateral inhibition

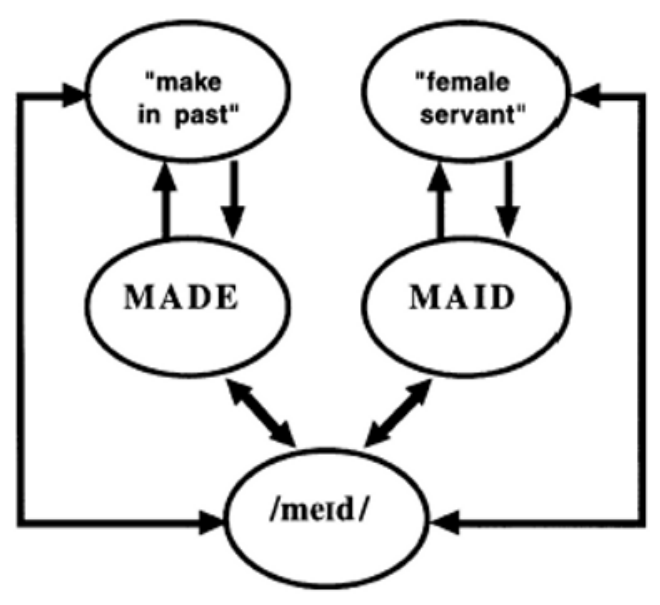

Without lateral inhibition

Figure 1. A generic network model for word recognition involving semantic, orthographic, and phonologic codes, applied to the case of polarized heterographic homophones such as /meId/ (where MADE has a higher printed frequency than MAID). In the left-hand panel, lateral inhibitory connections allow the most frequent orthographic and sem antic representations to dominate processing (bold lines). In the right-hand panel the absence of lateral inhibition allows activation of both dominant and subordinate representations.

and meanings. In the absence of lateral inhibition (righthand panel), both orthographic forms and meanings of heterographic homophones remain activated in the absence of any conflicting contextual information. In the left-hand panel of Figure 1, lateral inhibitory connections allow the most frequent orthographic and semantic representations to dominate processing in a winner-take-all competition. Thus according to the model with lateral inhibition, given sufficient processing time, only the dominant orthographic and semantic representations should remain activated. On the other hand, the model without lateral inhibition predicts that all form and meaning representations should remain activated in the absence of any biasing context.

Early evidence for frequency-sensitive selection processes was obtained using the semantic priming paradigm where prime stimuli were homographs with strongly polarized ambiguities - that is, where one meaning occurs much more frequently than the other (Simpson, 1981). For example, in their classic study, Simpson and Burgess (1985) varied prime-target stimulus onset asynchrony (SOA) while measuring semantic priming effects from the dominant and subordinate meanings of ambiguous prime words (e.g., BAT-BALL; BAT-FLY). They found evidence of initial activation of both meanings followed by selection of the dominant meaning (see Marqueur, Lebreton, Léveillé, \& Dionisio, 1990, for a similar time course analysis in French). Both the dominant and subordinate meanings produced facilitatory priming relative to unrelated controls at 100- and 300-msec SOAs, while only the dominant meaning produced significant facilitation at 500- and 750-msec SOAs. Vu et al. (1998) have recently presented evidence for activation of both dominant and subordinate meanings of homographs presented following neutral sentence contexts. However, the effective SOA in this study was on average $265 \mathrm{msec}$; hence the results are in line with those obtained by Simpson and Burgess (1985). Thus, a comparison of effects obtained at different SOAs (although caution must be exercised when comparing experiments using different stimuli and different stimulus presentation conditions) suggests that after a critical amount of processing (estimated at around $500 \mathrm{msec}$ ) of highly polarized homograph stimuli, only the dominant meaning remains activated in the absence of any biasing context. In the present study, we examine whether this is true for auditorily presented stimuli at an effective SOA of $580 \mathrm{msec}$ (the average duration of the auditory word primes used in our study).

One possible criticism of these semantic priming studies is that it might be the mechanism underlying semantic priming that is frequency sensitive and not the mechanism that allows meaning to be retrieved from ambiguous words. Thus, participants may be more likely to predict a word related to the high-frequency meaning (e.g., predict BALL given BAT) than one related to the low-frequency meaning (e.g., predict FLY given BAT). Such predictive mechanisms would be operational only at relatively long SOAs (Neely, 1991). On the other hand, automatic semantic priming may not be frequency sensitive, thus explaining the time course of semantic priming from ambiguous primes.

In the present study, we addressed such criticism by directly testing performance on the dominant and subordinate words themselves. This is possible in a cross-modal priming paradigm with heterographic homophones. When presented as auditory primes, these stimuli are ambigu- 
ous, but as visually presented targets there is no longer any ambiguity. Thus, participants listened to heterographic homophones (e.g., /meId/) with a distinct frequency bias in their two possible interpretations (e.g., MADE vs. MAID). They then had to make a lexical decision response to one or the other of the printed forms of the homophone. Performance to homophone targets preceded by the corresponding homophone prime was compared with an unrelated prime condition.

According to the model without lateral inhibition in Figure 1, both the dominant and the subordinate orthographic and semantic representations should be activated following presentation of a heterographic homophone. Both dominant and subordinate targets should therefore benefit from auditory-visual repetition priming (MarslenWilson, 1990). In this case homophonic targets should behave in the same way as nonambiguous targets and therefore priming effects should not interact with homophone status. On the other hand, according to the model with lateral inhibition, only the dominant orthographic and semantic representations will be significantly activated following presentation of a heterographic homophone. Thus dominant targets should benefit from auditoryvisual repetition priming, whereas subordinate targets should not. Since, given the prior results of MarslenWilson, we expect to observe similar-sized repetition priming effects for low- and high-frequency nonhomophones, the critical prediction for Experiment 1 is a triple interaction between target word frequency, priming, and homophone status. The triple interaction should reflect the presence of a significant two-way interaction between priming condition and homophone status for low-frequency targets only. High-frequency targets should not show this two-way interaction.

\section{EXPERIMENT 1}

\section{Method}

Participants. Forty psychology students at René Descartes University, Paris, participated in the experiment in partial fulfillment of course requirement. All were native speakers of French, had normal or corrected-to-normal vision, and reported no hearing impairment.

Stimuli and Design. Forty pairs of French heterographic homophones (e.g., HEURE-HEURT; CHAT-CHAS) were selected in such a way that one form had a low printed frequency (average 6 occurrences per million) and the other a higher printed frequency (average 93 occurrences per million, Imbs, 1971). Length ranged from three to seven letters for the written forms, and all but four were monosyllabic (see Appendix for a list of the stimuli). A second set of 80 nonhomophonic high- (average 92 per million) and low-frequency (average 6 per million) target words were also selected. Each of these was closely matched for printed frequency and length in letters with the homophone to which it was associated.

Each printed target word, whether a homophone or not, was paired with two auditorily presented primes: one of them corresponding to the auditory form of the target (e.g., /sha/-CHAT), the other having minimal semantic, phonetic, and orthographic overlap with it. Thus, homophone status (homophone or not), frequency (high or low), ${ }^{1}$ and priming condition (repeated or unrelated) were crossed in a $2 \times$ $2 \times 2$ factorial design. In order to avoid participants' being pre- sented with a given target word more than once, or with both written forms of a given homophone, four experimental lists were constructed so that /sha/-CHAT, for example, was tested in one list, /sha/- CHAS in the second, CHAT with its frequency-matched control prime in a third list, and finally CHAS with its frequency-matched control prime in the fourth. Prime-target pairings were rotated across lists so that each participant (associated with a single list) saw 10 items in each of the eight combinations of target type $\times$ frequency $\times$ priming condition.

Eighty nonwords were constructed for the purposes of the visual lexical decision task. They were all orthographically legal, pronounceable, meaningless letter strings. Half of them were coupled with an orthographically related auditory word prime (that shared all letters but one with the nonword target associated to it, e.g., /tjar/-TIURE), whereas the other half was preceded by a totally unrelated auditory prime word. The word primes used with nonword targets were matched overall for length and frequency to the word primes used with word targets. The 80 nonwords and their respective priming conditions remained the same for all groups.

Items were presented to all participants in the same predetermined pseudorandom order to prevent the successive presentation of more than three items belonging to the same category (word/nonword) and/or priming condition. All auditory stimuli were recorded on one channel of a digital audiotape in a sound-attenuated room by a female native speaker of French. Prior to the recording, the homophonic words had been transcribed in phonetic alphabet, so as to avoid a possible influence of their spelling on the speaker's pronunciation. The recorded stimuli were then sampled at a $44-\mathrm{Hz}$ rate with Audiomedia, and a signal, corresponding to the perceptive offset of each prime, was placed on the second channel of the tape. This signal, inaudible to the participants, served to trigger the immediate presentation of the corresponding visual target on the center of the display screen. Auditory stimuli had an average duration of $580 \mathrm{msec}$ (range $=280-750 \mathrm{msec}, S D=135 \mathrm{msec}$ ), and stimulus duration was matched across the different prime categories.

Procedure. Participants were tested individually, and each experimental session lasted approximately $30 \mathrm{~min}$. They sat in a dimly lit room in front of a computer screen, wearing headphones through which they heard the prime words. Directly after hearing each auditory prime word, they saw a letter string on the screen (the interstimulus interval [ISI] was approximately zero). They were then required to indicate as rapidly and as accurately as possible whether the presented string was a French word or not by pressing one of the two response buttons. Participants responded "word" with the forefinger of their preferred hand and "nonword" with the foref inger of the other hand. The following trial was initiated after $1.5 \mathrm{sec}$. Visual targets were presented in lowercase letters with appropriate accents. Each character covered about $0.38^{\circ}$ of visual angle from the viewing distance of approximately $60 \mathrm{~cm}$, so each item subtended from $1.14^{\circ}$ to $2.66^{\circ}$, depending on its length. Response times (RTs) were measured (to the nearest millisecond) from target onset until participants' response. Targets remained on the screen until participants' responded or the time-out period $(1,500 \mathrm{msec})$ was reached. Before doing the experiment proper, participants were presented with 32 practice trials, consisting of items belonging to the same categories as the experimental words and nonwords just described. The experimental trials followed the practice session without a break.

\section{Results}

Means of the RTs for correct responses and percent errors to word targets in each stimulus category and priming condition are given in Table 1.

RT data. All latencies less than $300 \mathrm{msec}$ or greater than 1,500 msec were excluded from the RT analysis 
Table 1

Mean Reaction Times (RTs, in Milliseconds) and Percentage Error (PE) to Word Targets in the Different Experimental Conditions of Experiment 1 (No Pseudohomophones Present)

\begin{tabular}{|c|c|c|c|c|c|c|c|c|}
\hline \multirow[b]{3}{*}{ Condition } & \multicolumn{4}{|c|}{ High Frequency } & \multicolumn{4}{|c|}{ Low Frequency } \\
\hline & \multicolumn{2}{|c|}{ Homophone } & \multicolumn{2}{|c|}{ Nonhomophone } & \multicolumn{2}{|c|}{ Homophone } & \multicolumn{2}{|c|}{ Nonhomophon } \\
\hline & RT & $\mathrm{PE}$ & RT & $\mathrm{PE}$ & RT & $\mathrm{PE}$ & RT & $\mathrm{PE}$ \\
\hline Repeat & 521 & 1.0 & 522 & 1.8 & 676 & 18.3 & 552 & 5.5 \\
\hline Unrelated & 622 & 4.3 & 628 & 5.0 & 746 & 21.0 & 705 & 15.0 \\
\hline Net priming effect & 101 & 3.3 & 106 & 3.2 & 70 & 2.7 & 153 & 9.5 \\
\hline
\end{tabular}

( $0.5 \%$ of the data). Analyses of variance (ANOVAs) by participants $(F 1)$ and items $(F 2)$ were performed on these data with priming condition (repeated or unrelated prime) as a within-subjects and within-items factor and frequency (high or low), and target type (homophonic or not) as within-subjects but between-items factors. The significance level adopted in the present study is .05 .

There was a significant triple interaction $[F 1(1,39)=$ $\left.10.72, M S_{\mathrm{e}}=2,863 ; F 2(1,156)=12.09, M S_{\mathrm{e}}=4,109\right]$. As can be seen in Table 1, this reflects the larger priming effects obtained to nonhomophones as opposed to homophones for the low-frequency targets $[F 1(1,39)=33.39$, $\left.M S_{\mathrm{e}}=1,850 ; F 2(1,79)=19.29, M S_{\mathrm{e}}=6,023\right]$, whereas there is practically no difference for high-frequency targets. However, facilitatory priming was obtained for both the low-frequency homophone $\left[F 1(1,39)=23.74, M S_{\mathrm{e}}=\right.$ 4,$\left.119 ; F 2(1,39)=8.72, M S_{\mathrm{e}}=7,276\right]$ and the lowfrequency nonhomophone targets $[F 1(1,39)=189.70$, $\left.M S_{\mathrm{e}}=2,464 ; F 2(1,39)=112.89, M S_{\mathrm{e}}=4,770\right]$.

Error data. Two ANOVAs (by participant and by item) were performed on the error rates in each experimental condition. The triple interaction was not statistically robust. The only two-way interaction to reach statistical significance was between frequency and homophone status $\left[F 1(1,39)=38.78, M S_{\mathrm{e}}=53 ; F 2(1,156)=6.17\right.$, $\left.M S_{\mathrm{e}}=392\right]$. This interaction reflects the poorer performance to low-frequency homophones relative to the lowfrequency nonhomophone targets. There was a main effect of priming condition $\left[F 1(1,39)=37.99, M S_{\mathrm{e}}=46\right.$; $\left.F 2(1,156)=23.18, M S_{\mathrm{e}}=78\right]$, with fewer errors to targets preceded by repetition primes relative to unrelated primes.

Nonword analysis. The RT and error data to nonword targets were analyzed with priming condition (related or unrelated prime) as a within-subjects and between-items factor. Nonwords were more rapidly classified as such following a related auditory prime $(679 \mathrm{msec})$ than when preceded by unrelated primes $[714 \mathrm{msec}, F 1(1,39)=$ $\left.28.51, M S_{\mathrm{e}}=871 ; F 2(1,78)=4.68, M S_{\mathrm{e}}=9,837\right]$. False positive error rate was the same $(17.5 \%)$ in the related and the unrelated prime conditions.

\section{Discussion}

In Experiment 1, the auditory presentation of a heterographic homophone facilitated the subsequent visual recognition of the dominant form in the same manner as high-frequency nonhomophonetargets. On the other hand, the subordinate printed forms showed significantly smaller priming effects than matched low-frequency nonhomophone stimuli. Nevertheless, the low-frequency homophone targets did show significant priming, suggesting that both meanings of the homophone remain active to some extent following prime word presentation. These results are at least partly in line with the lateral inhibition model presented in the left-hand panel of Figure 1, since the low-frequency homophone targets do indeed behave differently from matched low-frequency nonhomophones. However, the fact that significant facilitatory priming was obtained to low-frequency homophone targets suggests that the effects of lateral inhibition are somewhat limited.

There are two possible reasons why the low-frequency homophones showed significant facilitatory priming in Experiment 1. Both of these are based on the idea that participants used some form of phonologic response strategy when making their visual lexical decision response. The least interesting explanation supposes that participants were adopting a sound-match strategy to make their lexical decisions. On every trial in which the visually presented target word sounded like the previously presented auditory prime, the correct response was invariably a "yes" response. Participants could therefore have adopted a strategy whereby fast positive responses would be given as soon as they detected a sound match between prime and target. Such a strategy should be applied independently of whether targets were homophones or not, and independently of target word frequency. However, the high error rate for low-frequency homophone targets in the repeated-prime condition (18.3\%) clearly indicates that participants were not applying such a strategy, at least not in any systematic way in the present experiment. It appears that our participants were indeed attempting to recognize words, and they found the subordinate forms of the homophone stimuli rather difficult. Furthermore, a sound-match strategy would tend to eliminate effects of word frequency on homophone targets in the related-prime condition. On the contrary, frequency effects for homophone targets were even larger in the related than in the unrelated condition.

A theoretically more interesting, and in our opinion more viable, explanation assumes that visual lexical decision could be performed on the basis of activity in wholeword phonologic representations, particularly when these have benefited from facilitatory phonologic priming, and therefore have higher activation levels than their 
orthographic counterparts (Ferrand \& Grainger, 1996; Grainger \& Ferrand, 1994). Responses based on wholeword phonology would allow participants to avoid the inhibitory influences operating at the level of whole-word orthographic representations and/or word meanings. Thus, in the left-hand panel of Figure 1, responses to visually presented heterographic homophones based on orthographic and/or semantic representations will suffer from lateral inhibition, while responses based on phonologic codes will not. Furthermore, if high-frequency words are assumed to have some form of activation advantage relative to low-frequency words (e.g., McClelland \& Rumelhart, 1981), then responses generated from phonological representations will mainly arise in the case of lowfrequency stimuli. Given their higher activation levels, high-frequency words are more resistant to lateral inhibition, and can therefore generate fast responses based on orthographic and/or semantic representations, with minimal influence of phonology. This explains why a healthy word frequency effect is observed for homophone targets in Experiment 1, since fast orthographic processing will generate an advantage for the high-frequency homophones.

In Experiment 2, pseudohomophonestimuli (nonwords that can be pronounced like a real word; e.g., BRANE) were added to the nonword targets. Any phonologic response strategy would lead to false positive errors with pseudohomophone targets (i.e., responding that BRANE is a word). Participants will therefore be forced to base their responses on either orthographic or semantic representations. The predictions of the lateral inhibition model, in terms of interaction effects, are the same as for Experiment 1 (triple interaction reflecting a significant two-way interaction between priming and homophone status only for low-frequency words). However, we now expect to see priming of low-frequency homophone targets reduced to null effects or even inhibition. On the other hand, according to the model without lateral inhibition, depicted in the right-hand panel of Figure 1, homophone targets should show priming effects that are similar to those obtained with nonhomophonetargets, independently of word frequency.

\section{EXPERIMENT 2}

\section{Method}

Participants. Sixty psychology students at René Descartes University, Paris, participated in the experiment for course credit. All were native speakers of French, with normal or corrected-to-normal vision, and no known hearing problem. None of them had taken part in the previous experiment.

Stimuli and Design. Word stimuli were the same as in Experiment 1 . Only the nonword stimuli were modified. Half of the nonwords from Experiment 1 were retained and the other half replaced by French pseudohomophone stimuli (an English example of a pseudohomophone is BRANE-pronounced like the word BRAIN). As in the first experiment, each nonword was preceded either by a related word prime or a totally unrelated word. For nonhomophonic nonwords, the related-word primes were orthographically and phonologically similar to the nonword target, as in Experiment 1. For the pseudohomophone stimuli, the related prime was the soundalike real word. The pseudohomophones varied in orthographic overlap with their base words, differing by one (e.g., ROUJE-ROUGE) or several letters (e.g., SAIRE-SERRE). This mimicked the varying orthographic overlap across homophone pairs.

Procedure. The procedure was the same as for the first experiment.

\section{Results}

Means of the lexical decision latencies and error rates are given for the word targets in Table 2, and the nonword targets in Table 3.

Reaction time data. All latencies less than $300 \mathrm{msec}$ or greater than $1,500 \mathrm{msec}$ were excluded from the RT analysis $(0.6 \%$ of the data). ANOVAs by participants $(F 1)$ and items $(F 2)$ were performed on these data.

The triple interaction was significant $[F 1(1,59)=44.14$, $\left.M S_{\mathrm{e}}=2,079 ; F 2(1,156)=6.14, M S_{\mathrm{e}}=7,226\right]$. This allows us to examine the critical priming condition $\times$ homophone status interaction separately for each frequency class. Of primary interest here is that this interaction was significant for low-frequency targets $[F 1(1,59)=101.57$, $\left.M S_{\mathrm{e}}=2,864 ; F 2(1,78)=11.88 M S_{\mathrm{e}}=10,546\right]$. This partial two-way interaction reflects a facilitatory priming effect obtained for low-frequency nonhomophone targets $\left[F 1(1,59)=136.69, M S_{\mathrm{e}}=3,084 ; F 2(1,39)=59.92\right.$, $\left.M S_{\mathrm{e}}=4,669\right]$ and an inhibitory trend obtained with the low-frequency homophone targets $[F 1(1,59)=3.48$, $\left.M S_{\mathrm{e}}=3,704, p<.10 ; F 2<1\right]$. The priming condition $\times$ homophone status interaction was not significant for highfrequency targets.

Error data. Two ANOVAs (by participant and by item) were performed on the error data. There was a significant main effect of priming condition $[F 1(1,59)=20.39$, $\left.M S_{\mathrm{e}}=70 ; F 2(1,156)=16.37, M S_{\mathrm{e}}=113\right]$ that did not significantly interact with the other factors. The triple interaction was not significant. The only two-way interaction to reach statistical significance was between frequency and homophone status $\left[F 1(1,59)=55.01, M S_{\mathrm{e}}=\right.$

Table 2

Mean Reaction Times (RTs, in Milliseconds) and Percentage Error (PE) to Word Targets in the Different Experimental Conditions of Experiment 2 (With Pseudohomophones)

\begin{tabular}{|c|c|c|c|c|c|c|c|c|}
\hline \multirow[b]{3}{*}{ Condition } & \multicolumn{4}{|c|}{ High Frequency } & \multicolumn{4}{|c|}{ Low Frequency } \\
\hline & \multicolumn{2}{|c|}{ Homophone } & \multicolumn{2}{|c|}{ Nonhomophone } & \multicolumn{2}{|c|}{ Homophone } & \multicolumn{2}{|c|}{ Nonhomophone } \\
\hline & RT & $\mathrm{PE}$ & RT & $\mathrm{PE}$ & RT & $\overline{\mathrm{PE}}$ & RT & $\mathrm{PE}$ \\
\hline One & 553 & 1.7 & 536 & 1.7 & 734 & 23.2 & 581 & 9.0 \\
\hline Unrelated & 627 & 6.0 & 635 & 6.5 & 714 & 22.2 & 698 & 14.7 \\
\hline Net priming effect & 74 & 4.3 & 99 & 4.8 & -20 & -1.0 & 117 & 5.7 \\
\hline
\end{tabular}


Table 3

Mean Reaction Times (RTs, in Milliseconds) and Percentage Error (PE) to Nonword Targets in the Different Experimental Conditions of Experiment 2

\begin{tabular}{lrrrrr}
\hline & \multicolumn{2}{c}{ Pseudohomophones } & & \multicolumn{2}{c}{ Nonhomophones } \\
\cline { 2 - 3 } \cline { 6 - 6 } \multicolumn{1}{c}{ Condition } & RT & PE & & RT & PE \\
\hline Repeat & 666 & 9.7 & & 686 & 13.7 \\
Unrelated & 718 & 19.3 & & 690 & 6.5 \\
Net priming effect & 52 & 9.6 & & 4 & -7.2 \\
\hline
\end{tabular}

$\left.67 ; F 2(1,156)=4.77, M S_{\mathrm{e}}=389\right]$. The effects of frequency were more than twice as large for homophone than for nonhomophone targets, and a homophone disadvantage (more errors to homophone targets than to nonhomophones) was observed only with low-frequency targets.

Nonword analysis. The RTs for correct responses to nonword stimuli were analyzed with type of nonword and priming condition as within-subjects and between-items factors. There was a significant interaction in the analysis by participants $\left[F 1(1,59)=32.72, M S_{\mathrm{e}}=1,090\right.$; $\left.F 2(1,76)=1.91, M S_{\mathrm{e}}=10,350\right]$. RTs to nonhomophonic nonwords were unaffected by prime-target relatedness, whereas pseudohomophones were recognized as nonwords more rapidly when preceded by a phonologically identical prime word relative to an unrelated prime $[F 1(1,59)=$ $\left.49.71, M S_{\mathrm{e}}=1,627 ; F 2(1,38)=6.85, M S_{\mathrm{e}}=7,144\right]$. An analysis of the error data showed a priming condition $X$ type of nonword interaction $\left[F 1(1,59)=10.49, M S_{\mathrm{e}}=\right.$ $\left.72 ; F 2(1,76)=4.87, M S_{\mathrm{e}}=104\right]$. Pseudohomophones were more accurately classified as nonwords when preceded by a phonologically identical prime than by an unrelated prime word, while there was an inhibitory effect of priming condition for nonhomophonic nonwords.

\section{Discussion}

The results of Experiment 2 show the pattern of effects predicted by the model with lateral inhibition depicted in the left-hand panel of Figure 1. The auditory presentation of a heterographic homophone facilitated the visual recognition of the high-frequency printed form in the same manner as repetition priming of nonhomophonic high-frequency words. On the other hand, while lowfrequency nonhomophone targets showed slightly larger priming effects than their high-frequency counterparts, the low-frequency homophone targets showed a trend suggesting inhibition. This caused a significant interaction between homophone status and priming effects for the low-frequency targets.

It was predicted that the presence of pseudohomophone stimuli as distractors in a visual lexical decision task would force participants to abandon a phonologic response strategy for making visual lexical decisions. According to this account, in Experiment 2 participants performed the lexical decision task mainly using either orthographic or semantic information. In the model with lateral inhibition depicted in the left-hand panel of Figure 1, only the codes corresponding to the dominant form and meaning of a heterographic homophone will attain significant activation levels during the auditory processing of such stimuli. This therefore accounts for why facilitatory repetition priming was observed only for the dominant targets.

The pseudohomophonetargets of Experiment 2 showed facilitation from the prior auditory presentation of their real-word counterpart. On the other hand, the nonhomophonic nonwords showed no priming effect. This led to faster RTs and fewer errors to pseudohomophone targets than to regular nonwords in the related-prime condition. This observation stands in direct opposition to what is usually termed a "pseudohomophone effect" (as defined by a slowing down of RTs to pseudohomophones relative to nonhomophonic nonwords, e.g., Stone \& Van Orden, 1993). This can be explained, however, by the cross-modal presentation procedure used here, and the strategies developed by participants to deal with pseudohomophone targets. Presentation of the prime word would provide information that could be used by participants to reject the pseudohomophone target as a nonword. In the repeatedprime condition, the prime stimulus provides spelling information (assumed to be automatically derived from the auditory stimulus) that can then help participants detect the fact that the spelling of the pseudohomophone target does not correspond to the real word with that particular pronunciation. Thus, for example, on hearing the word "brain," the corresponding orthographic representation would be automatically activated, hence providing the correct spelling of that word. Participants could then use this information to help them recognize that the printed target BRANE is not in fact a word. Regular nonword targets, on the other hand, can be rejected without any form of orthographic check (by insufficient lexical activation, for example, Grainger \& Jacobs, 1996), independently of the prime condition. The fact that these nonwords generated more errors following related prime words can be explained by the greater degree of lexical activation generated in this situation compared to the unrelated prime condition.

The nonhomophone targets tested in Experiment 2 showed very similar amounts of priming in the high-and low-frequency target conditions. This change in the pattern of results relative to Experiment 1 is due essentially to the low-frequency repetition-prime condition, which generated slower RTs and more errors in Experiment 2. Given that orthographic processing is slower for words of low printed frequency, as argued in the discussion of Experiment 1, it is this precise condition that should benefit most from the application of a phonologic response strategy. Thus, when such a strategy can no longer be applied, it is this specific condition that shows the greatest increase in RTs and errors in the presence of pseudohomophone stimuli in Experiment 2.

\section{GENERAL DISCUSSION}

Two experiments tested two hypotheses relative to the processing of heterographic homophones in the absence 
of biasing context. The cross-modal priming paradigm was used with homophone and nonhomophone stimuli. With homophone stimuli, ambiguous auditory primes (e.g., /meId/) were followed by either the dominant (highfrequency) or subordinate (low-frequency) printed form (e.g., MADE or MAID), and priming effects for these highand low-frequency targets were evaluated relative to an unrelated prime word. In Experiment 1, strong facilitatory priming was obtained to both homophone and nonhomophone targets, and to both high- and low-frequency words. A different pattern of results was obtained in Experiment 2 by introducing pseudohomophones among the nonword stimuli. Pseudohomophones were used to force participants to generate a lexical decision response on the basis of either orthographic or semantic codes, while ignoring phonology. As can be seen in the left-hand panel of Figure 1, it is in this precise situation that the effects of lateral inhibition should be strongest, thus modifying the priming effects obtained with subordinate targets. This was indeed the case. In Experiment 2, the dominant meanings continued to show strong facilitation, as in Experiment 1 , whereas the subordinate meanings now showed numerically longer RTs following repetition primes relative to unrelated primes.

The pattern of results obtained in Experiment 2 confirms prior observations of a frequency-based selection process for strongly polarized ambiguous words when given sufficient processing time (Marqueur et al., 1990; Simpson \& Burgess, 1985). In the absence of any biasing context, the lexical processor eventually settles on a unique interpretation of the ambiguous stimulus as a function of the relative frequency of the different meanings. In the left-hand panel of Figure 1, this frequency-sensitive selection mechanism is described in terms of lateral inhibition operating across representations at the same level. The most frequent phonologic-orthographic-semantic correspondences (depicted in bold in the figure) have an initial processing advantage that allows them to gradually suppress the activation of the less frequent representations. This particular theoretical stance predicts that visually presented subordinate forms of heterographic homophones should suffer interference from the dominant form. On presentation of MAID, the phonologic form /meId/ will be activated, thus leading to activation of the dominant orthographic form MADE. Lateral inhibitory connections across orthographic nodes will then slow down the processing of the stimulus word. We now turn to examine the evidence that this is indeed the case.

Interference effects in the processing of ambiguous words. Visual lexical decision responses to the subordinate form of heterographic homophones (e.g., MAID) have been shown to be slower than nonhomophonic control words in certain experimental conditions (Davelaar, Coltheart, Besner, \& Jonasson, 1978; but see Pexman, Lupker, Jared, Toplak, \& Rouibah, 1996, for contrary evidence). A recent study by Folk (1999) provides further evidence using eye movement measures in sentence reading. The subordinate printed forms of heterographic homophones were presented in sentences that were neutral prior to the ambiguous word and disambiguating thereafter (e.g., Jim said that thyme was a hardy plant to grow in the herb garden). Eye movement measures indicated inflated processing, relative to unambiguous control sentences, in the disambiguating region following the ambiguous word, with more regressions back to the ambiguous word. These results imply that there was some activation of the dominant inappropriate interpretation of the ambiguous word (TIME in the given example), thus generating interference in processing of the correct interpretation. This is an example of second-order effects of ambiguity, in that the ambiguity arises only after transcoding of the stimulus (from orthographic to phonologic codes in the present example). ${ }^{2}$

The present study provides converging evidence on this issue. In the unrelated-prime condition of Experiment 1, the subordinate forms took $41 \mathrm{msec}$ longer to accept as words (with $6 \%$ more errors) than the nonhomophonic control words, while the dominant forms were $6 \mathrm{msec}$ faster (with $1 \%$ fewer errors) than the corresponding controls. ${ }^{3}$ The high-frequency mate appears to interfere in the recognition of these otherwise unambiguous lowfrequency printed forms (MAID is ambiguous only once its pronunciation has been activated).

Further evidence in favor of such second-order ambiguity effects have recently been observed in a study of crosslanguage ambiguity. Dijkstra, Grainger, and van Heuven (1999) examined the visual processing of English words that varied in their orthographic, phonologic, and semantic overlap with Dutch words in Dutch-English bilingual participants. While shared orthography and semantics always facilitated processing, shared phonology inhibited processing. RTs were slower to English words such as LEAF than to their matched unambiguous control words (LEAF is not a homograph of a Dutch word but is homophonic with a Dutch word, LIEF, which means "lovely"). This is the bilingual counterpart of within-language heterographic homophones. Visual presentation of LEAF will activate the phonologic node /lif/, which will then provide feedback to the alternative orthographic form LIEF, hence interfering in the recognition of the target word.

Finally, Gottlob et al. (1999) have shown that naming latencies and semantic association judgments were slower to visually presented heterophonic homographs (e.g., LEAD) relative to nonambiguous controls. This, however, is evidence for first-order interference effects (since the stimulus is immediately ambiguous) rather than the type of second-order interference observed in the present experiment and the Dijkstra et al. (1999) study. Secondorder interference in the processing of heterophonic homographs can be tested by presenting the subordinate phonologic form (e.g., /lid/) auditorily. In this case, the automatic activation of the corresponding orthographic form could generate activation of the dominant phonologic form $(/ \mathrm{lEd} /)$ and inhibit processing of the subordinate target. To our knowledge no such experiment has been published.

Pseudohomophone influences on homophone processing. The inclusion of pseudohomophones among the 
nonword targets in Experiment 2 was predicted to stop participants from applying a phonologic response strategy, hypothesized to be responsible for the results obtained in Experiment 1. When pseudohomophonesare presented as targets, such a phonologic response strategy would generate too many false positive errors to such stimuli, hence forcing participants to abandon the strategy. One important question is, how exactly could such strategic control of response generation operate?

In order to limit the number of false positive errors made to pseudohomophone targets, some means of blocking, or at least ignoring the activity in whole-word phonological representations, must be applied. This could be achieved by selectively inhibiting all whole-word phonologic representations, thus allowing orthographic and semantic codes to dominate processing. In this case strategic control of response generation is seen as a form of top-down attentional control implemented by selective inhibition. Alternatively, criteria for response generation could be adjusted so that higher levels of activity in whole-word phonologic representations are required before a positive response would be triggered. Either of these mechanisms would reduce the amount of positive lexical decisions generated by whole-word phonologic representations, hence capturing the change in pattern of results between Experiments 1 and 2 in the present study.

One piece of evidence suggests that the influence of pseudohomophone targets is specifically located at the level of whole-word phonology. Ferrand and Grainger (1996) manipulated the presence/absence of pseudohomophone stimuli as targets (i.e., the same manipulation as across Experiments 1 and 2 in the present study) in a masked priming study in French. In this case, primes are presented visually on the same screen location as target words, for very brief durations (approximately $60 \mathrm{msec}$ ) and preceded by a forward pattern mask. Primes were either homophones of target words (an English example would be MADE-MAID), pseudohomophones of target words (e.g., MAYD-MAID), or unrelated to the target. Effects of pseudohomophone primes (relative to unrelated control primes) were unaffected by whether or not there were pseudohomophones among the nonword targets. On the other hand, masked homophone priming effects turned from strong facilitation when no pseudohomphones appeared as targets to strong inhibition in the presence of pseudohomophone distractors (see also Grainger \& Ferrand, 1994). This dissociation in the influence of pseudohomophone targets on masked priming effects from pseudohomophone and homophone primes suggests that the presence of pseudohomophone targets is selectively affecting whole-word phonology.

In conclusion, the present experiments provide evidence in favor of frequency-based selection during the processing of ambiguous words when presented in the absence of any biasing context. One means of accomplishing such a frequency-based selection is provided by lateral inhibitory networks in which frequency provides the critical head start for the dominant representation of the ambiguous stimulus. The present results also provide fur- ther confirmation that performance in a visual lexical decision task can be phonologically driven when phonologic representations provide the fastest means of accurate responding. The presence of pseudohomophone targets undermines a dominantly phonologic response strategy and forces participants to assign more weight to orthographic and/or semantic codes when making visual lexical decisions.

\section{REFERENCES}

Davelaar, E., Coltheart, M., Besner, D., \& Jonasson, J. T. (1978). Phonological recoding and lexical access. Memory \& Cognition, 6 , 391-402.

Dijkstra, T., Grainger, J., \& van Heuven, W. J. B. (1999). Recognition of cognates and interlingual homographs: The neglected role of phonology. Journal of Memory \& Language, 41, 496-518.

Dijkstra, T., Roleofs, A., \& Fieuws, S. (1995). Orthographic effects on phoneme monitoring. Canadian Journal of Psychology, 49, 264-271.

Donnenwerth-Nolan, S., Tanenhaus, M. K., \& Seidenberg, M. S. (1981). Multiple code activation in word recognition: Evidence from rhyme monitoring. Journal of Experimental Psychology: Human Learning \& Memory, 7, 170-180.

FERrand, L., \& Grainger, J. (1996). List context effects on masked phonological priming in the lexical decision task. Psychonomic Bulletin \& Review, 3, 515-519.

FoLK, J. R. (1999). Phonological codes are used to access the lexicon during silent reading. Journal of Experimental Psychology: Learning, Memory, \& Cognition, 25, 892-906.

Gottlob, L. R., Goldinger, S. D., Stone, G. O., \& Van Orden, G. C. (1999). Reading homographs: Orthographic, phonologic, and semantic dynamics. Journal of Experimental Psychology: Human Perception \& Performance, 25, 561-574.

Grainger, J., \& Ferrand, L. (1994). Phonology and orthography in visual word recognition: Effects of masked homophone primes. Journal of Memory \& Language, 33, 218-233.

Grainger, J., \& JACOBS, A. M. (1996). Orthographic processing in visual word recognition: A multiple read-out model. Psychological Review, 103, 518-565.

Imвs, P. (1971). Etudes statistiques sur le vocabulaire français: Dictionnaire des fréquences. Vocabulaire littéraire des XIXe et XXe siècles. Paris: Librairie Marcel Didier.

Jacobs, A. M., Rey, A., Ziegler, J. C., \& Grainger, J. (1998). MROM$\mathrm{p}$ : An interactive activation, multiple read-out model of orthographic and phonological processes in visual word recognition. In J. Grainger \& A. M. Jacobs (Eds.), Localist connectionist approaches to human cognition (pp. 147-188). Hillsdale, NJ: Erlbaum.

JAKIMIK, J., Cole, R. A., \& RUdNicky, A. I. (1985). Sound and spelling in spoken word recognition. Journal of Memory \& Language, 24, 165-178.

Marqueur, P., Lebreton, M., Léveillé, M., \& Dionisio, C. (1990). A quel moment du traitement des homographs intervient la fréquence relative de leurs acceptions? [Which stage of homograph processing is affected by relative frequency of meanings?] Année Psychologique, 90, 489-509.

Marslen-Wilson, W. M. (1990). Activation, competition, and frequency in lexical access. In G. T. M. Altmann (Ed.), Cognitive models of speech processing (pp. 148-172). Cambridge, MA: MIT Press.

McClelland, J. L., \& Rumelhart, D. E. (1981). An interactive activation model of context effects in letter perception: Part 1. An account of basic findings. Psychological Review, 88, 375-405.

NeEly, J. (1991). Semantic priming effects in visual word recognition: A selective review of current findings and theories. In D. Besner \& G. W. Humphreys (Eds.), Basic processes in reading: Visual word recognition (pp. 264-336). Hillsdale, NJ: Erlbaum.

Pexman, P. M., Lupker, S. J., Jared, D., Toplak, M., \& Rouibah, A. (1996, November). Strategically controlling phonology in response to pseudohomophones? Paper presented at the annual meeting of the Psychonomic Society, Chicago. 
Plaut, D. C., McClelland, J. L., Seidenberg, M. S., \& PatterSON, K. (1996). Understanding normal and impaired word reading: Computational principles in quasi-regular domains. Psychological Review, 103, 56-115.

Seidenberg, M. S., \& Tanenhaus, M. K. (1979). Orthographic effects on rhyme monitoring. Journal of Experimental Psychology, Human Learning, \& Memory, 5, 546-554.

Simpson, G. (1981). Meaning dominance and semantic context in the processing of lexical ambiguity. Journal of Verbal Learning \& Verbal Behavior, 20, 120-136.

Simpson, G. (1994). Context and the processing of ambiguous words. In M. A. Gernsbacher (Ed.), Handbook of psycholinguistics (pp. 359374). San Diego: Academic Press.

Simpson, G., \& Burgess, C. (1985). Activation and selection processes in the recognition of ambiguous words. Journal of Experimental Psychology: Human Perception \& Performance, 11, 28-39.

Stone, G. O., Vanhoy, M. D. , \& Van Orden, G. C. (1997). Perception is a two-way street: Feedforward and feedback phonology in visual word recognition. Journal of Memory \& Language, 36, 337-359.

Stone, G. O., \& Van Orden, G. C. (1993). Strategic control of processing in word recognition. Journal of Experimental Psychology: Human Perception \& Performance, 19, 744-774.

Tanenhaus, M. K., Flanigan, H. P., \& Seidenberg, M. S. (1980). Orthographic and phonological activation in auditory and visual word recognition. Memory \& Cognition, 8, 513-520.

VAN Orden, G. C., \& Goldinger, S. D. (1994). Interdependence of form and function in cognitive systems explains perception of printed words. Journal of Experimental Psychology: Human Perception \& Performance, 20, 1269-1291.
Vu, H., Kellas, G., \& Paul, S. T. (1998). Sources of sentence constraint on lexical ambiguity resolution. Memory \& Cognition, 26, 979-1001.

Ziegler, J. C., \& FerRAnd, L. (1998). Orthography shapes the perception of speech: The consistency effect in auditory word recognition. Psychonomic Bulletin \& Review, 5, 683-689.

Ziegler, J. C., Montant, M., \& Jacobs, A. M. (1997). The feedback consistency effect in lexical decision and naming. Journal of Memory \& Language, 37, 533-554.

\section{NOTES}

1. Word frequency rather than dominance will be used to describe this experimental variable since this applies to both types of target word. The terms dominant and subordinate will be used to refer specifically to polarized ambiguous words, in line with standard practice.

2 . The distinction we draw between first- and second-order effects of ambiguity is akin to the distinction drawn between feedforward (spellingto-sound) and feedback (sound-to-spelling) consistency (Stone, Vanhoy, \& Van Orden, 1997; Ziegler, Montant, \& Jacobs, 1997). Visually presented heterophonic homographs (e.g., LEAD) are feedforward inconsistent at a grain size corresponding to whole words (as well as other grain sizes), while heterographic homophones (e.g., MAID) are feedback inconsistent. What is critical, for both types of distinction, is the number of computational steps necessary to generate the ambiguity given a particular modality for stimulus presentation.

3 . The corresponding interaction (frequency $\times$ homophone status) for the unrelated-prime trials was highly significant in an analysis of the RT data for word targets $\left[F 1(1,39)=56.72, M S_{\mathrm{e}}=2,734 ; F 2(1,156)=\right.$ $\left.30.52, M S_{\mathrm{e}}=6,635\right]$.

\section{APPENDIX}

List of the Heterographic Homophones and the Corresponding Unrelated Primes Tested in the Present Experiments

\begin{tabular}{|c|c|c|c|c|c|c|c|}
\hline High Frequency & Control & Low Frequency & Control & High Frequency & Control & Low Frequency & $\overline{\text { Control }}$ \\
\hline AIR & MUE & AIRE & NOIX & MORT & GARE & MORS & SENS \\
\hline BANC & VEUF & BAN & ANE & SOL & $\mathrm{ECU}$ & SOLE & OBUS \\
\hline FIL & AME & FILE & STAR & ENCRE & GERME & ANCRE & TRAME \\
\hline CHAT & BLEU & CHAS & ETUI & CHAUD & VENDU & CHAUX & POEME \\
\hline GAZ & POT & GAZE & CAFE & CHAMP & TRAIT & CHANT & LIGNE \\
\hline STATUE & PAQUET & STATUT & ENIGME & ROUE & DOME & ROUX & NEUF \\
\hline MOU & VIN & MOUE & FLOT & MARE & PUCE & MARC & DAME \\
\hline POIDS & ORDRE & POIX & OURS & PEINE & TACHE & PENNE & REMOUS \\
\hline CHAIR & POIRE & CHAIRE & AVENUE & PORT & ROSE & PORE & GOUT \\
\hline HEURE & SIEGE & HEURT & SAUCE & BALAI & FILET & BALLET & ALERTE \\
\hline FIN & NID & FAIM & IODE & LIT & CLE & LIE & SUD \\
\hline TARD & INNE & TARE & $\mathrm{CHOU}$ & COMPTE & DEFAUT & COMTE & VALVE \\
\hline COIN & ANGE & COING & ORAGE & MUR & POT & MURE & IRIS \\
\hline DESSIN & TOQUE & DESSEIN & MALAISE & DATE & BETE & DATTE & HERBE \\
\hline PALAIS & BASSIN & PALET & VISION & COEUR & LIANE & CHOEUR & ANIMAL \\
\hline POINT & BENNE & POING & SINGE & PAIN & LUXE & PIN & ARC \\
\hline PIE & AXE & PIS & DON & SEL & FOU & SELLE & ANNEE \\
\hline CALE & DUEL & CAL & BUS & SPORT & HABIT & SPORE & PINCE \\
\hline LUTTE & POUCE & LUTH & DEFI & JOUE & POSE & JOUG & VOTE \\
\hline SIGNE & FUSIL & CYGNE & SUITE & DANSE & VENIN & DENSE & MUSEE \\
\hline
\end{tabular}

(Manuscript received May 22, 1998;

revision accepted for publication March 1,2000.) 